\title{
To What Extent Does Accent Sensitivity Provide the Foundation for Lexical Knowledge and Listening Comprehension?
}

\author{
Arthur D. Meerman', Sachiko Kiyama', Katsuo Tamaoka ${ }^{3}$ \\ ${ }^{1}$ Faculty of Literature, Kurume University, Kurume, Japan \\ ${ }^{2}$ Neuroimag \& Informatics Lab, National Center for Geriatrics and Gerontology, Ohbu, Japan \\ ${ }^{3}$ Graduate School of Languages and Cultures, Nagoya University, Nagoya, Japan \\ Email: arthur meerman@kurume-u.ac.jp, skiyama@ncgg.go.jp, ktamaoka@lang.nagoya-u.ac.jp
}

Received 8 July 2014; revised 9 August 2014; accepted 17 August 2014

Copyright (C) 2014 by authors and Scientific Research Publishing Inc.

This work is licensed under the Creative Commons Attribution International License (CC BY). http://creativecommons.org/licenses/by/4.0/

(c) (7) Open Access

\section{Abstract}

The present study investigated the extent to which accent sensitivity provides the foundation for lexical knowledge and listening comprehension for Japanese university students learning English as a foreign language (EFL). On an English accent correctness (i.e., YES/NO response) decision task, 63 participants showed considerably high accuracy and speed in identifying correctly-accented nouns $(82.14 \%$ and $1091 \mathrm{~ms})$ and adverbs $(86.67 \%$ and $959 \mathrm{~ms})$. However, students were much less accurate in rejecting incorrectly-accented nouns $(72.33 \%$ and $910 \mathrm{~ms})$ and adverbs $(67.67 \%$ and $933 \mathrm{~ms}$ ). The results of a structural equation modeling (SEM) analysis showed that accent sensitivity makes no contribution to either participants' lexical knowledge or listening comprehension skills. In contrast, a strong direct effect was found from lexical knowledge to listening comprehension. As such, accent knowledge by Japanese EFL students is isolated from their lexical knowledge, with no contribution to their ability for listening comprehension.

\section{Keywords}

Accent Sensitivity, Lexical Knowledge, Listening Comprehension, Japanese EFL Students, Structural Equation Modeling (SEM)

\section{Importance of Accent in English}

It has long been understood that successful communication depends on word recognition (McQueen, 2007). Word knowledge includes phonological information such as phonemes, syllables and stress accents. Accent sen- 
sitivity, which refers to the ability to distinguish and interpret the distribution of accent stresses within a polysyllabic English word is fundamental to understanding English utterances. Indeed, accent placed on different syllables can affect lexical meaning entirely (e.g., ['prezent] meaning "in attendance", and [pre'zent] meaning "to give"). Furthermore, correctly positioned accent is key to listening comprehension in cases whereby lexical meaning can be inferred prior to the completion of an utterance. Taking the word "photographer", for example, the listener need only hear the accent on the first two of four syllables clearly (e.g., [fə'tagrəfər] to understand that the speaker is referring an individual, and not an image captured by camera.

However, the pronunciation of English words by native Japanese speakers is often markedly different from that of native English speakers. Using the name of the popular fast food chain as an example, "McDonald"s' [mək'danldz] is not only commonly pronounced without a stress accent/ma ku do na ru do/due to the effect of the Japanese phonological syllable or mora pattern, and is doubled in syllabic count. The difference in the role of lexical stress suggests that Japanese students of English may not be able to utilize accent information to access meanings of words and to apply to understanding spoken contexts, thereby hindering oral communication. The implications of lexical knowledge for listening comprehension have been extensively reported and discussed in previous studies (e.g., Baumann, 2005; Perfetti, 2010; Stæhr, 2009; Yamashita, 1999). On the other hand, although numerous textbooks are available for learning/teaching English stress accents (e.g., Beckman, 1986; Childs, 2004; Mojsin, 2009), little remains known as to the extent that EFL student accent sensitivity contributes to lexical knowledge and/or listening comprehension.

Since stress accents are integral to English words, accent sensitivity can be expected on logical grounds to contribute to lexical knowledge. If this is so, accent sensitivity may be further assumed to affect listening comprehension via lexical knowledge. The present study utilized Structural Equation Modeling (SEM), a statistical approach for testing and estimating causal relations among variables, to visually express the relationship among accent sensitivity, lexical knowledge and listening comprehension. Therefore, the present study investigated: 1) how quickly and accurately Japanese university EFL students can correctly identify canonical English stressaccent; 2) whether or not accent sensitivity is related to lexical knowledge; and 3) to what extent accent sensitivity, whether directly or via lexical knowledge, contributes to listening comprehension.

\section{Difficulty in Acquiring English Accents for Japanese Students}

There are several potential explanations for the difficulty encountered by Japanese learners of the English language in identifying correctly accented words. First, as mentioned above, Japanese pronounce each syllable with eq-ual-em-pha-sis (Mehler, Dommergues, Frauenfelder, \& Segui, 1981). Speakers of Japanese are not accustomed to using stress information in the same way as native English speakers.

Second, English loanwords and Japanized English ("wasei-eigo") expressions have become both widespread and entrenched in social parlance (Meerman \& Tamaoka, 2009). The common pronunciation of these words is, however, not in conformance with canonical accenting norms and therefore difficult for native English speakers to understand (let alone produce in a canonically incorrect way that Japanese can understand). Repeated exposure to mispronounced (i.e., incorrectly accented or stressed English) words that have become popularly entrenched in mainstream society would constitute both a frequency of occurrence bias (see Luce \& Pisoni, 1998) and a contextual constraint that inhibits their ability to correctly identify accurate pronunciation of English words.

Third, in addition to removing or altering the proper stress accent from English words in the process of borrowing them, representation in the seemingly ubiquitous katakana script has the unfortunate tendency of not only changing the pronunciation of letters (e.g., both "surprise" and "supplies" have identical katakana presentations), but also of adding considerably to the number of syllables in many words (see the previous example of "McDonalds", canonically a three-syllable name which assumes six syllables when pronounced in Japan). It can be safely assumed that doubling the number of syllables in this fashion renders it considerably more difficult for learners of English to determine correct accent placement.

Fourth, and related to the second, the use of the katakana script in language instruction to approximate pronunciation, and rote memorization or translation exercises for expediency purposes continues to be a common practice in classrooms. The emphasis of English language instruction in Japan on memorizing lexical meaning rather than producing correct pronunciation (including accenting) is a stubborn reflection of practical rather than ideal approaches to language instruction. 


\section{Study}

Accent sensitivity was measured by an experimental task asking Japanese EFL students to judge whether or not aurally presented nouns and adverbs exhibited canonical (i.e., native English) accenting. Lexical knowledge was measured by a paper-and-pencil test of nouns and adverbs. Listening comprehension was tested in six different themes, each of which consisted of three questions. Data resulting from this experimental approach led to the development of an SEM design consisting of three latent variables; namely, accent sensitivity, lexical knowledge and listening comprehension.

\subsection{Participants}

A total of 63 native Japanese speakers (51 female and 12 male) learning EFL at a Japanese private university in the Kyushu area participated in the present study. Both in terms of age and English proficiency in the four skills (i.e., reading, writing, listening, speaking), these participants were approximately at a middle rank among undergraduate university students, with a great majority being in the early half of their second year of study. The average age was 20 years and 5 months with a standard deviation of 1 year and 1 month, ranging from the youngest of 18 years and 7 months to the oldest of 23 years and 6 months.

\subsection{Accent Sensitivity}

Accent sensitivity was measured using an experiment using an accent correctness decision task. Stimuli of the experiment consisted of 40 correctly-accented and 40 incorrectly-accented nouns and adverbs, having more than three syllables. These basic lexical items were taken from a TOEIC Test preparatory textbook (Mizumoto \& Stafford, 2010). Recordings of half of the items (20 nouns and 20 adverbs) reflected proper accent placement, while the other half (20 adverbs and 20 nouns) exhibited incorrect accent placement (e.g., "transportation” presented with the incorrect accent ['trænspərteifn], and “occasionally” sounded in [əkeizə'nəli]). These stimuli were recorded by a male native English speaker from Canada. These 80 stimuli, 40 correct and 40 incorrect were aurally presented to each participant through noise-reduction headphones (all of the items are listed in the appendix). DMDX (3.2.6.4), experimental software developed by Jonathan C. Forster at the University of Arizona, was used for executing the accent correctness decision task, whereby participants were asked to judge whether or not a word exhibited correct (i.e., canonical) accenting. Both correctly and incorrectly-accented English nouns and adverbs were randomly presented to participants via computerized audio player, which began 600 milliseconds after pressing the space bar on a computer keyboard. Stimulus randomization was operated with each participant. Participants were instructed to respond as quickly and accurately as possible in deciding whether or not the word they heard conformed to canonical rules by pressing a YES or NO response key. Participants were allowed a maximum of 5 seconds to make their correctness decision. After each response, the participant pressed the space key to initiate the next presentation. Each response reaction time and its result of "correct" or "incorrect" was recorded by computer. The recording of reaction times started from the instant the space bar was pushed, as processing begins as soon as participants hear initial word sounds. Therefore, the duration of the whole auditory presentation is included in the measurement of the reaction time. Participants repeated this process until 80 correctly and incorrectly-accented items were presented. Ten practice trials were given to participants before the commencement of actual testing. Since they are more sensitive than accuracy rates, reaction times were taken to measure accent sensitivity for the SEM analysis.

\subsection{Listening Comprehension}

The first component of the experiment was a listening comprehension test comprising six short dialogues was composed by using items taken from existing TOEIC Test preparatory materials (Tsuruoka \& Malmgren, 2010). Short dialogues regarding the six themes of “trip”, "business”, “restaurant”, “newspaper”, “advertisement”, and "job hunting” were each followed by three multiple choice questions (one correct answer out of four choices). For example, in the case of the "trip" dialogue, participants had to choose one correct answer appropriately answering the question, "Why is the woman going to London?” with four options provided as potential answers: 1) To visit her brother; 2) To learn English; 3) To forget her home in Tokyo; 4) To attend her sister's wedding party. The correct answer is 5) if the participant selected; 6) s/he would receive one point. The latent variable of listening comprehension was measured by six observed variables of these six dialogues. 


\subsection{Lexical Knowledge}

Lexical knowledge was tested by a paper-and-pencil test comprising 40 multiple-choice questions, selecting one correct answer out of four choices. Word items were taken from existing TOEIC Test preparatory textbooks. Authors created three incorrect explanations. For example, a participant had to choose one correct answer appropriately explaining the meaning of the word, "equipment". Four explanations were provided as potential answers: 1) a serious medical condition; 2) an unusual weather pattern; 3) something used for a specific purpose; and 4) a political process. The correct answer is 5) If the participant selected; 6) s/he would receive one point. Since understanding of 40 items was solicited in the same way, the maximum score was 40 consisting of 20 nouns and 20 adverbs. The latent variable of lexical knowledge was measured by the two observed variables of nouns and adverbs.

\subsection{Procedure}

A period of one hour was allotted for participants to complete all components of the present tests and the experiment. This included an initial 10 minutes for the experimenter to solicit and register individual participant data as well as to overview the process of the experiment with participants, 45 minutes to run the actual experiment, and 5 minutes for movement from one participant group to another. Participants were tested in groups of up to four people at a time. The experiment commenced with the listening comprehension test, which was administered using room audio speakers to allow for simultaneous response time and hence an impartial environment. Listening comprehension items were played only once. Following the completion of the listening comprehension test, students were asked to quietly read a brief set of instructions outlining how to register their responses to accent items which was posted in front of their seats and written in large Japanese characters to ensure that there was no mistaking the experiment process. Participants then donned headphones and were instructed to begin the accent experiment. The third component of the present study, the lexical knowledge test, was distributed to students once all had completed the accent experiment and removed their headphones. Each participant was asked to answer each item as accurately as they could at his or her own pace. Again, participants were asked to place their pencils on their desks and wait quietly until all others had done the same, signifying the end of the study. Participants were given a token sum of money in appreciation for their participation.

\section{Results}

In this section, the results for the accent sensitivity, lexical knowledge and listening comprehension components of the experiment are presented. Test results include details regarding correlations and SEM analysis.

\subsection{Accent Sensitivity}

An accent correctness decision task for words presented auditorily was administered to 63 EFL students. The responses ("YES" for correctly-accented and "NO" for incorrectly-accented) are fundamentally different in cognitive processing, and therefore are analyzed separately. A separate $t$-test was conducted for these "YES" and "NO" responses to examine any difference between student understanding of English stress accenting for nouns and adverbs. All items used in measuring accent sensitivity are listed in the Appendix, with accuracy in percentages and reaction times in milliseconds.

Results for correct "YES" responses for correctly-accented nouns showed a mean response time of $1091 \mathrm{~ms}$ $(S D=149 \mathrm{~ms})$ and mean accuracy of $82.14 \%(S D=14.95 \%)$. The Pearson's product moment correlation between reaction times and accuracies for 20 nouns was $r=-0.623(p<0.01)$. The mean accuracy for the 20 nouns was higher than $80 \%$, with the word "amusement" showing the highest accuracy (95.24\%). This word is very common in mainstream Japanese society as an English loanword having the same accent position in both English and Japanese. One item, "conference” ['kanfərəns] was very low (33.33\%). This word is also sometimes used as a loanword in Japanese as/ka $\mathrm{N}$ fya re $\mathrm{N} \mathrm{su}$, but pitch accent position of this loanword may differ among native Japanese speakers. As a result, Japanese EFL students may have encountered various accenting of this word. It can be safely assumed that second year Japanese university students have had more frequent exposure to "amusement" than "conference"; the results for both of these words is furthermore understandable when the former follows canonical accenting norms in both languages, while the accenting of the latter is not widely uniform. 
Results for correct "YES" responses for correctly-accented adverbs showed a mean response time of $959 \mathrm{~ms}$ $(S D=266 \mathrm{~ms})$ and mean accuracy of $86.67 \%(S D=11.28 \%)$. The Pearson's product moment correlation between reaction times and accuracies for 20 adverbs was very high at $r=-0.887(p<0.001)$. Similarly, the mean accuracy of the 20 adverbs was higher than $86 \%$. Thus, the Japanese EFL participants performed very well in this task. The word "annually" showed $100 \%$ accuracy with a very fast average reaction time of $558 \mathrm{~ms}$, even though accent position differs between the canonical English rule and usage as an English loanword. An independent-samples $t$-test between nouns and adverbs showed no significant difference in either accuracy $[t(38)=$ $1.027, p=0.311, n s$. $]$ or reaction time $[t(38)=1.888, p=0.067, n s$.$] .$

Results for correct "NO" responses for incorrectly-accented nouns showed a mean response time of 910ms $(S D=115 \mathrm{~ms})$ and mean accuracy of $72.33 \%(S D=12.71 \%)$. The Pearson's product moment correlation between reaction times and accuracies for 20 nouns was not very high, at $r=-0.375(p=0.104, n s$.). Although the speed required to reject 20 incorrectly-accented nouns was fast, the mean accuracy was not very high. Results for correct "NO" responses for incorrectly-accented adverbs show a mean response time of $933 \mathrm{~ms}$ (SD = 110 $\mathrm{ms}$ ) and mean accuracy of $67.67 \%(S D=10.74 \%)$. The Pearson's correlation between reaction times and accuracies for 20 nouns was also not high at $r=-0.240(p=0.308, n s$.). The mean accuracy for the 20 incorrectly-accented adverbs was rather low. An independent-samples $t$-test between nouns and adverbs showed no significant difference in either accuracy $[t(38)=1.226, p=0.228, n s$. $]$ or reaction time $[t(38)=0.626, p=0.535$, ns.].

Reaction times for accurately accepting correctly accented nouns and adverbs, and for correctly rejecting incorrectly accenting nouns and adverbs are a more sensitive and informative measurement than accuracy rates. Reaction times alone are therefore used for the purposes of constructing the SEM analysis in the section below.

\subsection{Lexical Knowledge}

The latent variable of lexical knowledge was measured by two observed variables of nouns and adverbs consisting of 20 questions in each grammatical category (maximum of 40 points). The mean score was 28.84 with the standard deviation of 6.55. The Cronbach's reliability coefficient for the 40 test items as measured by 63 participants was very high, at $\alpha=0.853$. As shown in Table 1 , correlations with listening comprehension were fundamentally significantly high, showing 10 significant correlations and 2 non-significant.

\subsection{Listening Comprehension Test}

The latent variable of listening comprehension was measured by 18 questions consisting of six topics; namely, "trip", "business”, “restaurant”, "newspaper”, "advertisement”, and "job hunting”, each of which consisted of 3 questions. The mean score was 10.20 with a standard deviation of 2.74. The Cronbach's reliability coefficient for the 18 questions, at $\alpha=0.558$ as measured with 63 participants, was not outstanding but perhaps rather inevitable given the low number of questions.

\subsection{Overall Description of Correlations}

Means, standard deviations and correlations used for the SEM analysis are reported in Table 1. Decision times among noun and adverb accent acceptance ("YES" responses) and rejection ("NO" responses) were highly correlated, being over $r=0.700$ in all correlations. The highest correlation was observed between rejection times for incorrect accents between noun and adverbs $(r=0.888, p<0.001)$. The correlation of lexical knowledge between nouns and adverbs was also high, $r=0.759(p<0.001)$. Correlations between the six observed variables (or themes) of listening comprehension with lexical knowledge were reasonably high, except "advertisement" with adverbs $(r=0.018, n s$. $)$ and with nouns $(r=0.041, n s$.$) .$

\subsection{SEM Analysis}

Structural equation modeling (SEM) was carried out to investigate the degree of extent that accent sensitivity and lexical knowledge provide the foundation for listening comprehension. The SPSS AMOS 17.0J (2008) package was used to investigate a causal model constructed by three latent variables of accent sensitivity, lexical knowledge and listening comprehension. The result is depicted in Figure 1. The SEM analysis converged to create a solution with reasonable fit as reflected in the model $\left[n=63, \chi^{2}(51)=56.083, p=0.290, n s\right.$.; GFI $=$ 
Table 1. Means, standard deviations, and correlations for observed and latent variables in the three potential variables.

\begin{tabular}{|c|c|c|c|c|c|c|c|c|c|c|c|c|c|}
\hline$\#$ & $\begin{array}{l}\text { Observed } \\
\text { variables }\end{array}$ & 1 & 2 & 3 & 4 & 5 & 6 & 7 & 8 & 9 & 10 & 11 & 12 \\
\hline \multicolumn{14}{|c|}{ Accent sensitivity } \\
\hline 1 & $\begin{array}{l}\text { Speed of noun } \\
\text { accent rejection }\end{array}$ & ----- & & & & & & & & & & & \\
\hline 2 & $\begin{array}{l}\text { Speed of adverb } \\
\text { accent rejection }\end{array}$ & $0.888^{* * *}$ & ---- & & & & & & & & & & \\
\hline 3 & $\begin{array}{l}\text { Speed of noun } \\
\text { accent acceptance }\end{array}$ & $0.765^{* * *}$ & $0.733^{* * *}$ & ---- & & & & & & & & & \\
\hline 4 & $\begin{array}{l}\text { Speed of adverb } \\
\text { accent acceptance }\end{array}$ & $0.802^{* * * *}$ & $0.813^{* * *}$ & $0.800^{* * *}$ & ----- & & & & & & & & \\
\hline \multicolumn{14}{|c|}{ Lexical knowledge } \\
\hline 5 & Nouns & 0.161 & 0.156 & 0.117 & 0.106 & ----- & & & & & & & \\
\hline 6 & Adverbs & 0.005 & 0.001 & 0.051 & -0.016 & $0.759^{* * *}$ & ----- & & & & & & \\
\hline \multicolumn{14}{|c|}{ Listening comprehension } \\
\hline 7 & Trip & -0.039 & -0.053 & 0.057 & -0.008 & $0.456^{* *}$ & $0.505^{* * *}$ & & & & & & \\
\hline 8 & Business & 0.155 & 0.097 & $0.228^{*}$ & 0.184 & $0.221^{*}$ & $0.225^{*}$ & $0.234^{*}$ & & & & & \\
\hline 9 & Restaurant & -0.031 & -0.057 & -0.016 & -0.060 & $0.468^{* *}$ & $0.479^{* * *}$ & $0.331^{* *}$ & $0.255^{*}$ & & & & \\
\hline 10 & Newspaper & $0.252^{*}$ & 0.190 & 0.205 & 0.226 & $0.324^{* *}$ & $0.218^{*}$ & $0.324^{* *}$ & 0.064 & 0.152 & & & \\
\hline 11 & Advertisement & -0.021 & 0.037 & 0.073 & 0.029 & 0.041 & 0.018 & $0.218^{*}$ & 0.051 & 0.109 & $0.321^{* *}$ & & \\
\hline 12 & Job Hunting & -0.013 & -0.013 & 0.031 & -0.116 & $0.285^{*}$ & $0.327^{* *}$ & $0.349^{* *}$ & 0.023 & $0.290^{*}$ & $0.246^{*}$ & -0.117 & \\
\hline & Mean & 1149 & 1188 & 1074 & 931 & 15.16 & 13.62 & 1.43 & 1.49 & 2.62 & 1.56 & 1.11 & 2.00 \\
\hline \multicolumn{2}{|c|}{ Standard Deviation } & 513 & 430 & 396 & 333 & 3.091 & 3.924 & 0.946 & 0.780 & 0.633 & 0.894 & 0.625 & 0.880 \\
\hline
\end{tabular}

Note: $\mathrm{n}=63 ;{ }^{*} p<0.05 ;{ }^{* *} p<0.01 ;{ }^{* * *} \mathrm{p}<0.001$.

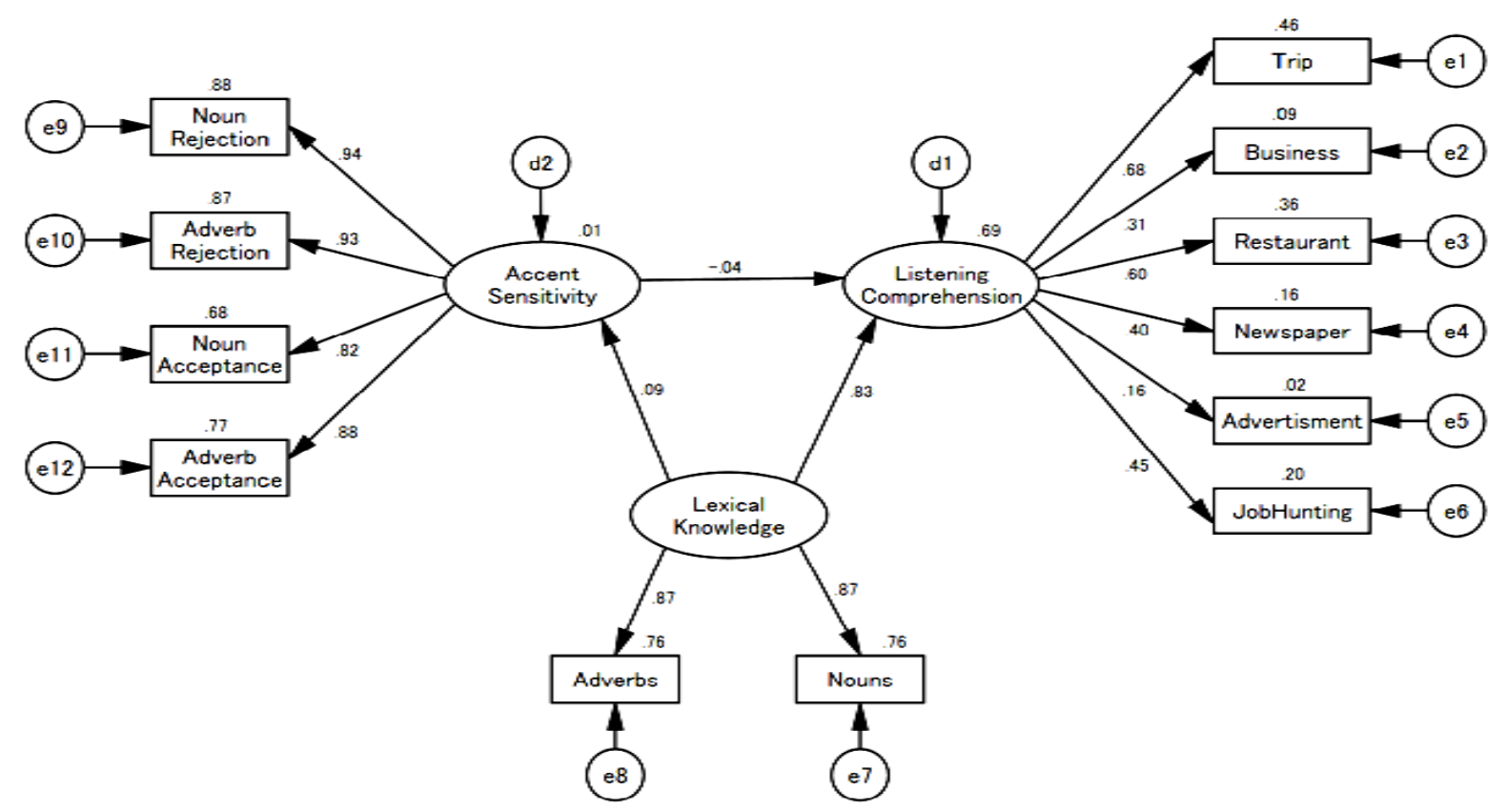

Figure 1. Causal relations of accent sensitivity, lexical knowledge and listening comprehension. Note: $n=63 ;{ }^{*} p<0.05 ;{ }^{* *} p<$ $0.01 ;{ }^{* * *} p<0.001$. 
0.881; AGFI $=0.818 ;$ CFI $=0.985 ;$ RMSEA $=0.040]$.

The four observed variables of accent sensitivity showed excellent factor loadings, all having higher than $\beta=$ $0.82(p<0.001)$. Likewise, the two observed variables of lexical knowledge also showed good factor loadings, both with $\beta=0.87(p<0.001)$. The six observed variables of listening comprehension showed a wide range of factor loading from the lowest $\beta=0.16$ (ns.) for "advertisement" to the highest $\beta=0.68(p<0.001)$ for "trip". Causal relations leading from accent sensitivity to lexical knowledge $(\beta=0.09, n s$.) and to listening comprehension $(\beta=-0.04, n s$.) were not significant. Lexical knowledge showed a significant contribution to listening comprehension ( $\beta=0.83, p<0.001$ ). Thus, only lexical knowledge affects listening comprehension.

\section{Discussion}

First, to what extent do Japanese EFL students exhibit sensitivity to English stress accents? Using the experimental approach of reaction time and accuracy, EFL students performed an English stress accent decision task for auditorily presented correctly and incorrectly-accented words. For correct YES responses, EFL students demonstrated high accuracy and speed at $82.14 \%$ and $1091 \mathrm{~ms}$ for correctly-accented nouns, and at $86.67 \%$ and $959 \mathrm{~ms}$ for correctly-accented adverbs. For correct NO responses, their accuracies were lower at $72.33 \%$ and $910 \mathrm{~ms}$ for incorrectly-accented nouns, and at $67.67 \%$ and $933 \mathrm{~ms}$ for incorrectly-accented adverbs. In terms of accent sensitivity, participants in the present experiment could therefore generally recognize what was correct, but had difficulty in identifying what was not.

Second, does English accent sensitivity contribute to lexical knowledge? Stress accents are lexical features; in other words, each English word has a unique stress accent. If so, accent sensitivity of Japanese EFL students should have a strong effect on lexical knowledge. However, contrary to our expectations, the SEM results of the present study found no significant contribution of accent sensitivity to lexical knowledge. Therefore, Japanese EFL students seem not to form close associations between stress accents and their corresponding lexical items.

Third, does accent sensitivity contribute directly to listening comprehension? The SEM results found no direct contribution of accent sensitivity to listening comprehension. In contrast, lexical knowledge showed a strong effect on listening comprehension. This result was congruent with causal relations between lexical knowledge and comprehension found in previous research (e.g., Baumann, 2005; Perfetti, 2010; Stæhr, 2009; Yamashita, 1999). Since it has already been proven that accent sensitivity does not directly affect lexical knowledge in the second question, the indirect effect of accent sensitivity on listening comprehension via lexical knowledge is not supported. Lexical knowledge is therefore a major contributor to listening comprehension.

In the present study, Japanese students performed reasonably well at identifying correctly-accented English words. This implies that they actually have, to a certain degree, accent sensitivity. However, this accent sensitivity does not contribute to students' lexical knowledge; in other words, students are not referring to accent placement in order to recall the meaning of a word. This finding was contrary to our initial expectations: Japanese university EFL students do not appear to memorize accents with word meanings, revealing no relationship between stress accents and lexical concepts, and no contribution of accent to listening comprehension. In that no casual relation from accent sensitivity to lexical knowledge was found among participants, there can naturally be no direct influence of accent sensitivity on listening comprehension.

Previous studies (e.g., Aull \& Zue, 1985; Cutler, 1984) show that native speakers of English rely upon lexical accent characteristics as fundamental information to deciding word meaning. The results of the present study, however, indicate that Japanese learners of English are not making sufficient use of accent placement in their studies. We consider that this reflects an instructional shortcoming of Japanese English education, and that more attention should be paid to teaching accent sensitivity to further contribute to both students' lexical knowledge and listening comprehension.

\section{References}

Aull, A., \& Zue, V. W. (1985), Lexical Stress Determination and Its Application to Large Vocabulary Speech Recognition. Acoustics, Speech, and Signal Processing, IEEE International Conference on ICASSP '85, 10, 1549-1552.

Beckman, M. E. (1986). Stress and Non-Stress Accents. Dordrecht, the Netherlands: Foris Publications. http://dx.doi.org/10.1515/9783110874020

Baumann, J. F. (2005). Vocabulary-Comprehension Relationships. In B. Maloch, J. V. Hoffman, D. L. Schallert, C. M. Fairbanks, \& J. Worthy (Eds.), Fifty-Fourth Yearbook of the National Reading Conference (pp. 117-131). Oak Creek, WI: 
National Reading Conference.

Childs, C. (2004). Improve Your American English Accent. New York: McGraw-Hill.

Cutler, A. (1984). Stress and Accent in Language Production and Understanding. In D. Gibbon, \& H. Richter (Eds.), Intonation, Accent and Rhythm: Studies in Discourse Phonology. Berlin: Walter de Gruyter. http://dx.doi.org/10.1515/9783110863239.77

McQueen, J. M. (2007). Eight Questions about Spoken-Word Recognition. In M. G. Gaskell (Ed.), The Oxford handbook of psycholinguistics (pp. 37-53). Oxford: Oxford University Press.

Meerman, A., \& Tamaoka, K. (2009). Japanese University EFL Student Understanding of Commonly-Used Japanized-English (Wasei-Eigo) Expressions. Bulletin of the Institute of Foreign Language Education (Kurume University), 16, 19-40.

Mizumoto, A., \& Stafford, M. (2010). Successful Keys to the TOEIC Test 1 and 2 (2nd ed.). London: Pearson Longman.

Mojsin, L. (2009). Mastering the American Accent. New York: Barron’s Educational Series.

Perfetti, C. (2010). Decoding, Vocabulary, and Comprehension. In M.G. McKeown, \& L. Mucan (Eds.), Bringing reading research to life (pp. 291-303). New York: The Guilford Press.

Stæhr, L. S. (2009). Vocabulary Knowledge and Advanced Listening Comprehension in English as a Foreign Language. Studies in Second Language Acquisition, 31, 577-607. http://dx.doi.org/10.1017/S0272263109990039

Tsuruoka, T., \& Malmgren, G. (2010). Get Your Best Marks for the TOEIC Test! Tokyo: Shohakusha.

Yamashita, J. (1999). Reading in a First and a Foreign Language: A Study of Reading Comprehension in Japanese (the L1) and English (the L2). Unpublished Ph.D. thesis, Lancaster University.

\section{Appendix: Stimulus Items}

Note: The figures following stimulus items refer to accuracy in percentage (\%) and reaction times in milliseconds (ms). Values were calculated by means of 63 EFL students.

Correctly-accented nouns for correct "Yes" responses:

amusement, 95.24, 818; committee, 95.24, 927; electricity, 95.24, 997; appointment, 95.24, 1152; maintenance, 93.65, 868; distribution, 93.65, 949; management, 92.06, 1032; component, 92.06, 1210; representative, 90.48, 895; temperature, 88.89, 1117; performance, 85.71, 1170; controller, 82.54, 1203; productivity, 80.95, 1265; resident, 76.19, 1071; instruction, 76.19, 1218; criminal, 73.02, 986; accommodation, 71.43, 1069; opportunity, 68.25, 1257; prescription, 63.49, 1305; conference, 33.33, 1315.

Correctly-accented adverbs for correct "Yes" responses:

annually, 100.00, 558; aggressively, 98.41, 552; temporarily, 98.41, 668; regularly, 96.83, 837; efficiently, 95.24, 614; industrially, 95.24, 683; competitively, 95.24, 873; evidently, 95.24, 967; obviously, 92.06, 805; valuably, 92.06, 918; thoroughly, 88.89, 1025; additionally, 88.89, 1072; appropriately, 87.30, 926; numerously, 80.95, 1054; completely, 79.37, 1134; politically, 76.19, 1077; eventually, 74.60, 1437; accurately, 69.84, 1221; fundamentally, 65.08, 1503; essentially, 63.49, 1263.

Incorrectly-accented nouns for correct "No" responses:

emergency, 91.67, 659; automobile, 90.00, 959; physician, 86.67, 860; destination, 86.67, 896; occupation, 83.33, 975; anniversary, 80.00, 987; responsibility, 78.33, 908; audience, 78.33, 855; instrument, 75.00, 858; transportation, 73.33, 790; reservation, 71.67, 901; negotiation, 71.67, 916; atmosphere, 70.00, 888; equipment, 70.00, 1028; quantity, 65.00, 859; environment, 63.33, 957; laboratory, 61.67, 883; administration, 56.67, 1171; recommendation, 51.67, 729; ceremony, 41.67, 1118.

Incorrectly-accented adverbs for correct "No" responses:

patiently, 85.00, 873; officially, 83.33, 785; personally, 80.00, 887; separately, 78.33, 1008; occasionally, 76.67, 838; physically, 75.00, 827; casually, 73.33, 857; uniquely, 73.33, 1058; conveniently, 73.33, 1063; frequently, 70.00, 839; approximately, 68.33, 1062; traditionally, 66.67, 940; honestly, 63.33, 964; surprisingly, 61.67, 850; internationally, 58.33, 990; generally, 56.67, 811; necessarily, 56.67, 911; definitely, 56.67, 1243; impressively, 50.00, 878; increasingly, 46.67, 970. 
Scientific Research Publishing (SCIRP) is one of the largest Open Access journal publishers. It is currently publishing more than 200 open access, online, peer-reviewed journals covering a wide range of academic disciplines. SCIRP serves the worldwide academic communities and contributes to the progress and application of science with its publication.

Other selected journals from SCIRP are listed as below. Submit your manuscript to us via either submit@scirp.org or Online Submission Portal.
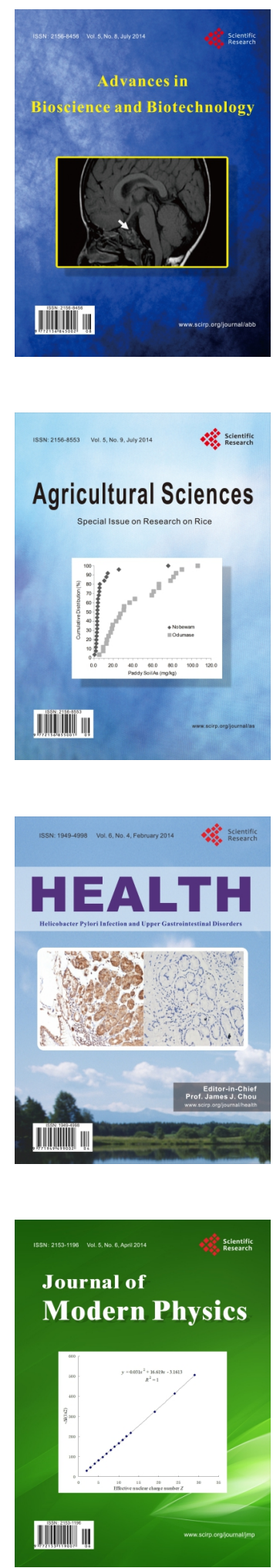
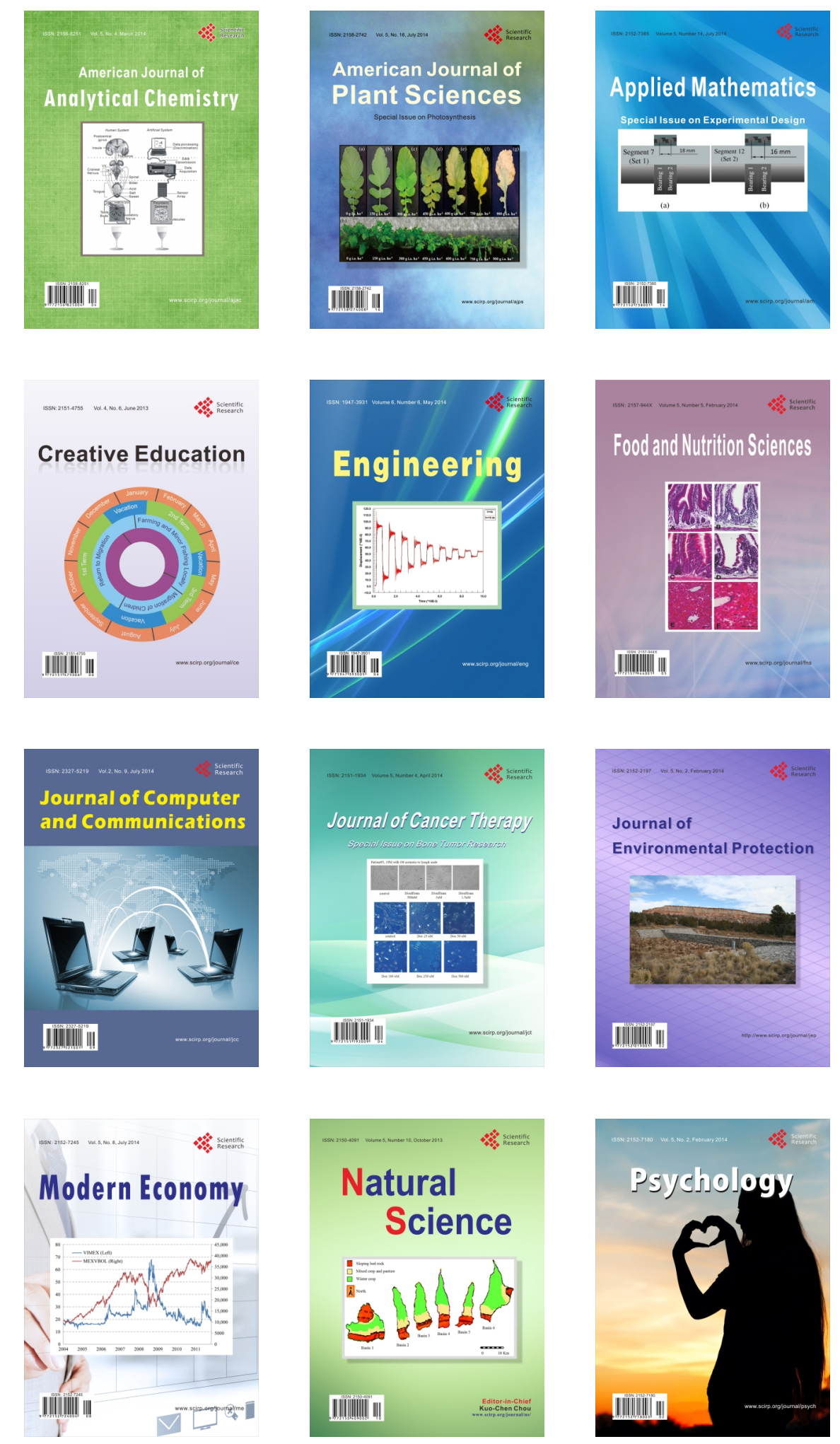